\title{
Substansi dan Formal Bentuk Usaha Tetap(BUT) Pada Strategi Pengurangan Pajak
}

\author{
Muhammad Rifky Santoso ${ }^{1^{*}}$ \\ ${ }^{1}$ Widyaiswara Kementerian Keuangan, Balai Diklat Keuangan Medan \\ Jl. Eka Warni No. 30 A, Medan Indonesia \\ *e-mail: m.rifky.santoso@gmail.com
}

\section{Artikel Info \\ Received : \\ 20 April 2020 \\ Revised : \\ 29 Mei 2020 \\ Accepted : \\ 9 Juni 2020}

\begin{abstract}
ABSTRAK
Dengan sistem self assessment dalam melakukan kewajiban perpajakan, maka otoritas pajak harus melakukan pemeriksaan agar strategi pengurangan pajak yang dilakukan wajib pajak bisa terdeteksi dan peneriman pajak bisa diterima secara optimal.Wajib pajak punya tujuan memaksimalkan profit dengan mengurangi pembayaran pajak. Adanya kekurangan peraturan perpajakan dalam penentuan bentuk usaha tetap (BUT), hubungan istimewa, dan penjabaran perjanjian penghindaran pajak berganda (P3B), bisa dimanfaatkan oleh wajib pajak, terutama wajib pajak dari luar negeri untuk pengurangan pembayaran pajak di Indonesia. Dengan menggunakan studi kasus pada Putusan Pengadilan Pajak di Indonesia, maka terlihat dengan mudahnya wajib pajak luar negeri melakukan strategi untuk pengurangan pajak. Dengan menyamarkan BUT menjadi hubungan bisnis dengan pihak independen, maka branch profit tax bisa dihindarkan dan pengeluaran untuk kantor pusat bisa sebagai cara pengurangan pajak dan cara transfer profit ke luar negeri. Kurangnya informasi yang dimiliki otoritas pajak mengenai wajib pajak dankurang lengkapnya peraturan perpajakan, menjadikan usaha wajib pajak dalam pengurangan pajak tidak bisa dicegah atau dikurangi secara optimal. Perlu upaya melengkapi peraturan terutama yang berhubungan dengan BUT bila ada transaksi yang secara substansi merupakan BUT namun secara formal bukan BUT, dan hubungan istimewa karena penggunaan teknologi, serta penjabaran P3B terutama istilah yang belum dijelaskan dalam $\mathrm{P} 3 \mathrm{~B}$, seperti istilah 'control'.
\end{abstract}

Kata kunci : bentuk usaha tetap, hubungan istimewa, teknologi, pengurangan pajak.

\section{Substance and Formal Permanent Establishment On The Tax Reductio Strategy}

\section{ABSTRACT}

With a self-assessment system in carrying out taxation obligations, the tax authority must conduct atax audit so that the tax reduction strategies conducted by taxpayers can be detected and tax revenues can be received optimally. Taxpayers have the aim of 
maximizing profits by reducing tax payments. The lack of tax regulations in determining permanent establishment (PE), associate enterprises (related party), and elaboration of double taxation avoidance agreements or tax treaty (P3B), can be used by taxpayers, especially taxpayers from abroad for reducing tax payments in Indonesia. By using a case study in the Tax Court Decision in Indonesia, it is easily seen that foreign taxpayers implement strategies for tax reduction. By disguising BUT as a business relationship with an independent party, branch profit tax can be avoided and expenses for head office can be a way of reducing taxes and transferring profits abroad. Lack of information possessed by tax authorities regarding taxpayers and incomplete tax regulations, making taxpayer businesses in tax reduction cannot be prevented or reduced optimally. Efforts should be made to complete regulations especially those relating to BUT if there are transactions that are substantially BUT but formally not $B U T$, and associate enterprises due to the use of technology, as well as the translation of a tax treaty, especially terms that have not been explained in P3Ba tax treaty, such as the term 'control'.

Keywords : Permanent establishment, Special relationship, Technology, Tax reduction.

\section{PENDAHULUAN}

Pemerintah Republik Indonesia mengandalkan penerimaan pajak dalam pembiayaan Negara, dan kondisi ini terlihat dari realisasi penerimaan pajak tahun 2010 sampai dengan 2014 (K. K. R. Indonesia, 2015) sebagaimana terlihat pada Tabel 1.

Tabel 1. Realisasi Penerimaan Negara Sektor Perpajakan (Rp. Milyar)

\begin{tabular}{lccccr}
\hline \multicolumn{1}{c}{ Uraian } & $\mathbf{2 0 1 0}$ & $\mathbf{2 0 1 1}$ & $\mathbf{2 0 1 2}$ & $\mathbf{2 0 1 3}$ & \multicolumn{1}{c}{$\mathbf{2 0 1 4}$} \\
\hline $\begin{array}{l}\text { Pendapatan Negara } \\
\text { dan Hibah }\end{array}$ & $995.271,5$ & $1.210 .599,7$ & $1.338 .109,6$ & $1.438 .891,1$ & 1.635 .378$, \\
\hline $\begin{array}{l}\text { Penerimaan } \\
\text { Perpajakan }\end{array}$ & $723.306,7$ & $873.873,9$ & $980.518,1$ & $1.077 .306,7$ & 1.246 .107$, \\
\hline Persentase & & & & & 0 \\
\hline
\end{tabular}

Sumber: Rencana Strategis Kementerian Keuangan, 2015-2019.

Rata-rata persentase penerimaan negara dari sektor perpajakan selama 5 tahun ini sebesar $73,84 \%$ dan persentase ini cenderung terus menaik setiap tahunnya. Fakta ini menunjukkan pentingnya penerimaan pajak bagi Negara dan oleh sebab itu Negara berusaha menambah penerimaan pajak ini dengan membuat kebijakan agar Wajib Pajak mau patuh membayar pajak.

Bagi Wajib Pajak, pembayaran pajak merupakan beban yang dapat mengurangi profit dan nilai perusahaan. Banyak riset yang membahas hubungan antara pengelakan pajak melalui perencanaan pajak, antara lain yang dilakukan oleh Wang (2010) yang menjelaskan bahwa perusahaan yang lebih transparan akan lebih baik dalam melakukan tax avoidance dan dapat meningkatkan nilai perusahaan, dan oleh Lee \& Swenson (2008) yang menjelaskan adanya perbedaan tarif pajak pada masing-masing Negara akan membuat perusahaan multinasional melakukan pengelakan pajak (tax avoidance). 


\section{EKONOMIKAWAN : Jurnal Ilmu Ekonomi dan Studi Pembangunan}

I55N : $1693-7600$ (Print), 155N : 2598-0157 (Online), hutp://fumal_umstiac.id//index.php/ekawan

Terdapat perbedaan kepentingan yang saling berlawanan antara Negara dan Wajib Pajak, sehingga masing-masing pihak akan melakukan upaya yang terbaik untuk kepentingan masing-masing. Dengan adanya usaha dari Wajib Pajak untuk melakukan pengurangan pajak, maka otoritas pajak di Indonesia, dalam hal ini Direktorat Jenderal Pajak (DJP) melakukan kebijakan pemeriksaan untuk memastikan bahwa Wajib pajak telah melakukan kewajiban perpajakannya dengan benar dan berkurangnya pengelakan pajak yang dilakukan Wajib Pajak di Indonesia. Namun demikian, hasil pemeriksaan yang dilakukan DJP bisa saja kurang maksimal karena berbagai sebab, dan hasil pemeriksaan ini menimbulkan sengketa serta tidak tercapainya tujuan pemeriksaan. Artikel ini membahas sengketa pajak yang telah menjadi keputusan pengadilan pajak yaitu putusan nomor PUT115980.15/2014/PP/M.IIIA Tahun 2018(Pajak, 2018).

Salah satu sengketa yang dibahas pada putusan ini adalah adanya klaim pembatalan penjualan oleh pembeli karena kualitas produk yang dijual tidak sesuai keinginan pembeli walaupun pembeli bertanggung jawab terhadap kualitas produk tersebut yang dimulai sejak pemesanan sampai pengiriman barang.Pada saat melakukan pemeriksaan, pemeriksa pajak tidak membahas adanya hubungan istimewa dan atau kemungkinan adanya hubungan bentuk usaha tetap (BUT) antara pembeli dan penjual yang merupakan strategi perpajakan dalam pengelakan pajak. Artikel ini membahas kasus Putusan Pengadilan Pajak ini serta menjelaskan bagaimana strategi pengelakan pajak yang dilakukan wajib pajak sehingga wajib pajak bisa mengurangkan pembayaran pajaknya di Indonesia. Dengan kurangnya informasi yang dimiliki oleh DJP mengenai wajib pajak, maka strategi pengurangan pajak yang dilakukan wajib pajak tidak dapat dideteksi oleh DJP.

\section{KAJIAN TEORI}

Theory of taxation yang dipelopori Adam Smith (1776) menerangkan negara mengumpulkan sumber dana dalam rangka memenuhi kebutuhan barang dan jasa publik. Untuk mencapai tujuan Negara Republik Indonesia, maka pemerintah Republik Indonesia memerlukan dana yang saat ini sebagian besar diperoleh dari pajak. Untuk memperoleh penerimaan pajak, maka beberapa hal harus diperhatikan yang menurut Adam Smith dikenal sebagai asas pemungutan pajak yaitu:

1. Asas Equality, yaitu pajak yang dipungut disesuaikan dengan kemampuan Wajib Pajak.

2. Asas Certainty, yaitu harus ada undang-undang dan peraturan yang jelas dalam pelaksanaan pemungutan pajak.

3. Asas Convenience of Payment, yaitu pemungutan pajak di saat yang tepat misalnya saat Wajib Pajak menerima penghasilan.

4. Asas Efficiency, yaitu beban pemungutan pajak seminimal mungkin.

Agar pemungutan pajak sesuai dengan asas yang dijelaskan oleh Adam Smith, maka otoritas pajak harus bisa membangun administrasi pajak yang baik yang salah satunya adalah melakukan pemeriksaan. Pemeriksaan pajak perlu dilakukan pada Negara yang menerapkan sistem self-assessment, yaitu wajib pajak diberi wewenang untuk menghitung, memperhitungkan, membayar, dan melaporkan pajak-pajaknya sesuai peraturan perpajakan. Otoritas pajak memastikan apakah laporan Wajib Pajak yang sehubungan dalam pelaksanaan kewajiban perpajakannya sudah sesuai atau belum dengan peraturan yang berlaku.

Kebijakan pemeriksaan harus memperhatikan beberapa risiko yang ada, sehingga strategi yang dilakukan bisa mengurangi aktifitas wajib pajak dalam melakukan pengurangan pajak. Strategi yang bisa dilakukan adalah (European Commission, 2006): 


\section{EKONOMIKAWAN : Jurnal Ilmu Ekonomi dan Studi Pembangunan}

I55N : $1693-7600$ (print), 155N : 2598-0157 (Online), http://Rumal.umsu.acid//ndex, php/ekawan

1. bertujuan menangkap wajib pajak yang melakukan pengelakan pajak cukup besar dalam rupiah,

2. bertujuan untuk mencegah wajib pajak menjadi pengelak pajak walaupun potensi untuk menjadi pengelak pajak masih kecil,

3. bertujuan menciptakan pencegahan lebih baik melalui individu wajib pajak dengan melakukan tindak lanjut audit, maksudnya, Wajib Pajak yang telah di audit dan terbukti melakukan pengelakan pajak, diaudit kembali,

4. bertujuan menciptakan pencegahan secara umum (general) dengan melakukan audit di area yang tepat menurut umum, misalnya melakukan audit Wajib Pajak yang melakukan pengelakan pajak dan yang mengaku memberikan manfaat sosial.

Pemeriksaan yang dilakukan oleh DJP dengan menggunakan data Surat Pemberitahuan (SPT) Tahunan pajak penghasilan (PPh) pada jangka waktu 2011 sampai 2016 menjelaskan bahwa pemeriksaan dapat mengurangi keinginan wajib pajak dalam pengurangan pajak (Penata \& Widyawati, 2018). Dalam mengukur pengurangan pajak ini, Penata \& Widyawati(2018) menggunakan pengukuran perubahan nilai Effective Tax Rate (ETR). Perubahan ETR yang positif diartikan bahwa kecenderungan melakukan pengurangan pajak telah berkurang. Namun demikian, berubahnya nilai ETR secara positif dapat juga diartikan bahwa hasil pemeriksaan pajak bisa mengakibatkan Wajib Pajak ditambah beban pajaknya pada tahun pajak yang diperiksa. Tidak ada jaminan di tahun akan datang Wajib Pajak akan naik nilai ETR nya karena berkurangnya pengelakan pajak.

Pemeriksaan pajak mempunyai pengaruh positif dalam mempengaruhi kepatuhan wajib pajak (Ompusungu \& Trisnawati, 2014) dan kepatuhan pajak ini diukur dengan adanya kemampuan dan kemauan wajib pajak untuk melaporkan, membayar pajak secara sukarela sesuai dengan peraturan pajak. Hasil penelitian oleh Ompusungu \& Trisnawati (2014) masih belum menjelaskan apakah tax avoidance masih tetap dilakukan atau tidak. Pengelakan atau pengurangan pajak bisa dilakukan baik secara legal (tidak melanggar peraturan perpajakan) maupun secara illegal (melanggar peraturan perpajakan)(Hanlon \& Heitzman, 2010; Lietz, 2013).

Patuhnya wajib pajak dalam melaporkan dan membayar pajak secara sukarela dapat diartikan juga tetap ada pengelakan pajak dengan memanfaatkan kelemahan peraturan pajak yang ada. Salah satu cara pengelakan pajak yang tidak melanggar aturan pajak adalah dengan melakukan tax sheltering (Lietz, 2013). Menurut Cambridge Dictionary, tax shelter adalah suatu perencanaan keuangan dengan melakukan investasi tertentu tanpa melakukan pembayaran pajak. Menurut Lisowsky (2010) dengan menggunakan referensi US Congress (1999), tax shelter adalah transaksi-transaksi yang dilakukan untuk mengurangi pajak tanpa ada risiko dan kerugian ekonomi. Tujuan utamanya adalah mengurangi pajak perusahaan dengan menggunakan peraturan perpajakan yang tidak lengkap. AICPA menjelaskan bahwa tax sheltering tidak mempunyai tujuan bisnis dan merupakan aktifitas pengurangan pajak tanpa melanggar aturan yang ada serta tidak punya substansi secara ekonomi.

Teori pengelakan pajak ini diperkenalkan oleh Allingham \& Sandmo (1972). Dalam melaporkan pajaknya, wajib pajak mempunyai 2 strategi yaitu:

1. melaporkan penghasilannya yang sebenarnya, dan

2. melaporkan penghasilan yang lebih kecil dari yang sebenarnya.

Bila wajib pajak melaporkan penghasilan yang lebih kecil dari yang sebenarnya, maka wajib pajak mempertimbangkan kemungkinan dilakukan audit dan dikenakan sanksi. Dalam perkembangannya, teori ini di kritisi oleh Alm, Martinez-vazquez, \& Wallace (2009), yang menjelaskan bahwa tidak ada informasi yang mencukupi dimiliki oleh 


\section{EKONOMIKAWAN : Jurnal Ilmu Ekonomi dan Studi Pembangunan}

I55N : $1693-7600$ (print), 155N : 2598-0157 (Online), hutp://fumal_umstiacid//index.php/ekawan

otoritas pajak, menyebabkan wajib pajak melakukan pengelakan pajak. Untuk mengurangi pengelakan pajak dan menambah penerimaan negara, maka negara membuat kebijakan tax amnesty (pengampunan pajak). Pengalaman yang dialami wajib pajak saat diperiksa, juga menciptakan persepsi dari wajib pajak dalam melakukan pengelakan pajak di masa akan datang setelah dilakukan pemeriksaan (Snow \& Warren, 2007).

Pengelakan pajak dengan perencanaan pajak (tax planning) yang dilakukan perusahaan memberikan hasil yang berbeda, tergantung dari skema yang dilakukan (Inger, 2014). Hasil penelitian Inger (2014) menjelaskan bahwa perusahaan yang menggunakan skema menahan penghasilan yang berasal dari luar negeri akan memberikan pengaruh yang negatif dan signifikan terhadap nilai perusahaan. Skema tax planning dengan menggunakan metode pembebanan biaya yang berbeda antara peraturan pajak dan akuntansi, tidak ada pengaruhnya secara signifikan terhadap nilai perusahaan.

\section{METODE}

Artikel ini menggunakan metode studi kasus dari putusan pengadilan pajak untuk mengetahui strategi apa yang dilakukan wajib pajak dalam upayanya melakukan pengelakan pajak di Indonesia. Pembahasan dimulai dengan menjelaskan transaksi yang menjadi sengketa dan kemudian menjelaskan apa yang menjadi sengketa pada kasus ini. Kemudian dijelaskan data pendukung yang di ketahui dari putusan pengadilan untuk melakukan analisis. Analisis data dilakukan untuk mengetahui apakah ada hubungan istimewa dan bentuk usaha tetap (BUT) dari pihak yang melakukan transaksi untuk pembahasan lebih lanjut dalam memahami tax planning yang dilakukan wajib pajak. Dari hasil analisis ini baru dilakukan pembahasan lebih lanjut.

\section{Transaksi}

Putusan Pengadilan Pajak Nomor PUT-115980.15/2014/PP/M.IIIA Tahun 2018 (Pajak, 2018) menyelesaikan sengketa atas hasil pemeriksaan oleh Direktorat Jenderal Pajak (DJP) terhadap koreksi peredaran usaha dan koreksi harga pokok penjulan. Koreksi peredaran usaha terjadi karena penyesuaian nilai faktur (invoice) dan klaim penolakan pembelian oleh pembeli karena kualitas produk tidak sesuai keinginan pembeli. Koreksi harga pokok penjualan dilakukan karena perbedaan penafsiran alokasi beban Asset Tak Berwujud. Artikel ini hanya pembahas transaksi yang berhubungan dengan koreksi peredaran usaha saja untuk mengetahui strategi pengelakan pajak yang dilakukan oleh wajib pajak.

Wajib Pajak (dalam putusan pengadilan ini disebut JAS) yang berlokasi di Indonesia melakukan penjualan ekspor kepada Arjowiggins Security SAS (Arjowiggins) yang ada di Prancis. JAS menjual produk ke Arjowiggins hanya berdasarkan pemesanan (purchase order). Pada tanggal 12 Desember 2014, terdapat penjualan sebesar jumlah tertentu ke Arjowiggins yang ditolak pembayarannya oleh Arjowiggins sebesar USD 4,714.75 karena terdapat kesalahan spesifikasi produk (kesalahan produksi).

Dalam melakukan proses produksi, JAS menerima purchase order (PO) dari Arjowiggins. Pada PO ini, disebutkan kualitas, kuantitas, dan biaya tetap (fixed cost) barang yang dipesan. Biaya variabel akan diperhitungkan pada saat produk selesai diproses. Proses produksi ini melalui 3 tahap pengawasan kualitas (quality control), yaitu:

1. pengawaasan atas datangnya bahan baku (incoming raw material),

2. pengawasan proses produksi (processing), dan

3. pengawasan saat barang keluar (outgoing goods).

JAS mengirimkan produk ini langsung ke pelanggan Arjowiggins, bukan ke Arjowiggins. Biaya pengiriman produk ini menjadi tanggung jawab Arjowiggins. JAS 
tidak melakukan kontak langsung dengan pelanggan akhir Arjowiggins. Skema transaksi yang menjadi sengketa ini terlihat pada Gambar 1.

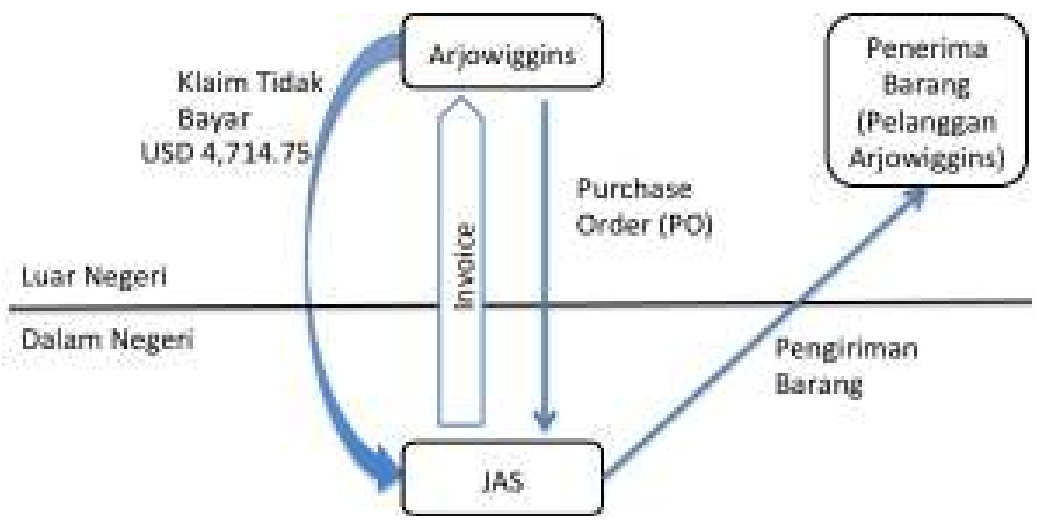

\section{Sengketa}

Gambar 1. Skema transaksi

Karena penjualan ke Arjowiggins tidak dibayar sebesar USD 4,714.75, maka JAS melakukan koreksi penjualannya. JAS menggunakan pencatatan dengan metode akrual yang berarti saat terjadi pengalihan hak atas barang sudah dicatat sebagai penjualan. Saat ada klaim untuk tidak membayar dari Arjowiggins, maka JAS melakukan koreksi atas penjualannya yang sebesar USD 4,714.75. Koreksi atas klaim ini oleh JAS tidak diakui oleh DJP dan menurut DJP seharusnya tidak ada koreksi dengan alasan:

1. penjualan ini ada di SPT Masa PPN JAS dan ini diakui oleh JAS.

2. Pemeriksa DJP tidak memperoleh bukti yang meyakinkan bahwa klaim itu benar terjadi karena hanya berupa 2 lembar credit note.

3. Karena detilnya pengawasan mutu dari Arjowiggins, maka kesalahan produksi hampir tidak mungkin terjadi.

JAS memberikan argumen bahwa:

1. Surat Pemberitahuan (SPT) masa Pajak Pertambahan Nilai (PPN) tidak bisa dibetulkan karena Pemberitahuan Ekspor Barang (PEB) yang sudah diterbitkan lebih dari 3 hari dan tidak dapat direvisi. Klaim yang diajukan oleh Arjowiggins diterima JAS setelah melewati batas waktu untuk merevisi PEB.

2. Uang yang diterima adalah sejumlah invoice dikurangi klaim. JAS tidak menerima uang sebesar klaim yang diajukan olehArjowiggins.

\section{Data Pendukung}

Data dari Contract Manufacturer Agreement antara JAS dan Arjowiggins menjelaskan:

1. PO dari Arjowiggins paling lambat 5 hari kerja sudah harus di jawab oleh JAS. Jawaban atas PO mencakup informasi tentang:

a. kuantitas pesanan

b. harga

c. tanggal pengiriman

2. Arjowiggins menyediakan SSB (Supplier Specification Booklet) untuk JAS. Pesanan yang dikerjakan JAS berdasarkan technical information dan kualitas bahan baku yang ada pada SSB. JAS dilarang mengubah apapun dalam proses produksinya tanpa persetujuan tertulis dari Arjowiggins.

3. Ketika Arjowiggins melakukan PO atas produk baru, maka JAS harus memberikan sampel produk ke Arjowiggins dan setelah disetujui baru dikirim produk baru tersebut 
sesuai dengan a certificate of conformity (COC) dan a quality control report (QC report).

Berdasarkan surat dari Arjowiggins pada tanggal 12 Desember 2014, JAS mengirimkan barang yang tidak sesuai dengan spesifikasi yang diminta oleh Arjowiggins dan Arjowiggins mengajukan klaim kerugian sebesar USD 4,714.75.

Catatan laporan keuangan JAS menjelaskan adanya Asset Tak Berwujud yang merupakan jasa teknis atas kualiti kontrol yang diberikan Arjowiggins kepada JAS tanggal 31 Januari 2014. Jasa teknis ini (Technical Service Agreement) akan diberikan Arjowiggins kepada JAS selama 5 tahun. Dari Technical Service Agreement diketahui bahwa:

1. Arjowiggins menyediakan dukungan dan layanan teknis yang berupa desain dan layout pabrik.

2. Dukungan teknis diberikan melalui kunjungan regular oleh tim Arjowiggins untuk mendukung proses produksi, indentifikasi dan pemecahan masalah, pengawasan mutu dan pengawasan pelaksanaan proses baru, serta pelatihan atas proses baru tersebut.

3. Arjowiggins memberikan dukungan teknis dalam pengelolaan proyek yang secara teknis kompleks di bidang inlay dan E-covers yang melibatkan manajemen produksi dan teknologi informasi, dan pengaturan lingkungan fasilitas.

4. Arjowiggins memberikan dukungan teknis dalam mengelola peningkatan dan kualitas proses, dan bekerja sama dengan tim dari JAS, serta memberikan laporan yang efisien dan terinci.

5. Biaya lump sum global sebesar USD 858,400 meliputi semua biaya dan pengeluaran dalam menyediakan layanan.

Dari laporan pemberian jasa, diketahui bahwa Arjowiggins sepanjang tahun 2014 telah memberikan dukungan teknis sebanyak 39 kali kedatangan. Dukungan yang diberikan oleh Arjowiggins ini dilakukan pada persiapan pabrik dan awal proses produksi yang ditujukan agar proses sesuai dengan standar yang ditetapkan Arjowiggins. Jangka waktu pemberian jasa ini selama 4 bulan.

JAS merupakan perusahaan pertama dan satu-satunya di Indonesia yang mampu memproduksi E-passport. Produksi E-passport ini membutuhkan teknologi tinggi serta teknik khusus terkait peletakan chip dan operating system yang terletak pada cover Epassport yang didukung dengan mesin khusus. Mesin untuk produksi yang dimiliki JAS dibeli dari Arjowiggins. Mesin yang dibeli ini mesin bekas. Harga mesin ini tidak termasuk instalasi dan training. Oleh karena itu dibutuhkan support dari Arjowiggins agar JAS bisa memproduksi produk yang dipesan Arjowiggins.

\section{HASIL DAN PEMBAHASAN}

Dari fakta dan data pada putusan pengadilan tersebut, pertama dilakukan adalah analisa untuk melihat apakah ada hubungan istimewa atau ada BUT antar pihak yang melakukan transaksi. Berikut adalah pembahasan mengenai hubungan istimewa dan BUT.

\section{Hubungan Istimewa}

Pasal 18 ayat (4) huruf b Undang-undang Nomor 36 Tahun 2008 Tentang Perubahan Keempat atas Undang-undang Nomor 7 Tahun 1983 Tentang Pajak Penghasilan (UU $\mathrm{PPh}$ (Undang-undang Nomor 36 Tahun 2008, 2008) menjelaskan bahwa hubungan istimewa menurut UU ini dianggap ada apabila Wajib Pajak menguasai Wajib Pajak lainnya atau dua atau lebih Wajib Pajak berada di bawah penguasaan yang sama baik langsung maupun tidak langsung. Penjelasan Pasal 18 ayat (4) UU PPh menerangkan 
bahwa hubungan istimewa di antara Wajib Pajak dapat terjadi karena ketergantungan atau keterikatan satu dengan yang lain yang disebabkan:

a. Kepemilikan atau penyertaan modal; atau

b. Adanya penguasaan melalui manajemen atau penggunaan teknologi.

Penjelasan Pasal 18 ayat (4) huruf b UU PPh menerangkan bahwa hubungan istimewa di antara Wajib Pajak dapat juga terjadi karena penguasaan melalui manajemen atau penggunaan teknologi walaupun tidak terdapat hubungan kepemilikan. Contoh hubungan istimewa karena penggunaan teknologi dijelaskan pada Surat Edaran Direktur Jenderal Pajak Nomor SE-18/PJ.53/1995 Tahun 1995 (Edaran, 1995), yaitu Perusahaan X yang memproduksi minuman Formula yang diciptakan oleh Perusahaan Y. Dalam hal ini ada penguasaan melalui penggunaan teknlogi oleh perusahaan $Y$ terhadap Perusahaan X, sehingga terjadi hubungan istimewa antara Perusahaan X dan Perusahaan Y. Contoh pada SE-18 ini menjelaskan teknologi diciptakan oleh pemilik, namun dalam UU PPh, tidak ada penjelasan apakah teknologi yang dimiliki tersebut diciptakan atau tidak diciptakan. Dengan merujuk ke UU PPh, selama ada penggunaan teknologi milik pihak lain dan ada ketergantungan atau keterikatan antara pemilik dan pengguna teknologi, maka ada hubungan istimewa antara pemilik dan pengguna teknologi.

Dengan menggunakan contoh dari SE-18/PJ.53/1995 di atas, tidak ada penjelasan lebih lanjut:

1. apakah penghasilan yang diterima oleh perusahaan $\mathrm{X}$ dari teknologi yang diciptakan perusahaan Y sebesar tertentu, misalnya harus 100\% atau lebih dari 50\%,

2. kepada siapa Perusahaan $\mathrm{X}$ menjual produknya, apakah kepada pihak yang mempunyai hubungan isitmewa atau pihak independen, atau

3. tingkat kerumitan atau kecanggihan teknologi yang digunakan.

Dengan demikian, selama ada penggunaan teknologi milik perusahaan lain, maka tercipta hubungan istimewa melalui penggunaan teknologi.

Pada kasus putusan pengadilan ini, tidak ada informasi apakah teknologi yang digunakan oleh JAS diciptakan atau tidak diciptakan oleh Arjowiggins, namun terdapat ketergantungan dan keterikatan antara JAS dan Arjowiggins dalam melakukan usahanya. Tidak terdapat juga data mengenai apakah semua penjualan JAS berasal dari PO yang diberikan Arjowiggins. Berdasarkan fakta dan peraturan perpajakan, dapat disimpulkan terdapat hubungan istimewa antara JAS dan Arjowiggins walaupun dari data tidak membuktikan adanya hubungan kepemilikan diantara keduanya.

Berdasarkan Article 9 P3B Indonesia Prancis yang menjelaskan Associated Enterprises (pihak yang mempunyai hubungan istimewa) dijelaskan bahwa hubungan istimewa terjadi bila :

1. suatu perusahaan dari negara dalam persetujuan berpartisipasi baik secara langsung maupun tidak langsung dalam manajemen, penguasaan (control), atau modal pada perusahaan di negara lain pada persetujuan, atau

2. orang yang sama berpartisipasi secara langsung atau tidak langsung dalam manajemen, penguasaan (control) atau modal dari satu perusahaan negara dalam persetujuan dan negara lain pada persetujuan.

P3B ini tidak menjelaskan secara rinci pengertian control, dan dari sektor apa saja control dapat terjadi. Oleh karena itu, untuk bisa dikatakan adanya control, maka Otoritas Pajak di Indonesia bisa menerapkan adanya control karena adanya penggunaan teknologi sebagaimana diatur dalam UU PPh. Dengan menggunakan Article 9 dari P3B Indonesia Prancis, maka antara JAS dan Arjowiggins terdapat hubungan istimewa karena control (penguasaan) yang dalam hal ini melalui penggunaan teknologi. 


\section{EKONOMIKAWAN : Jurnal Ilmu Ekonomi dan Studi Pembangunan}

I55N : $1693-7600$ (print), 155N : 2598-0157 (Online), hutp://fumal_umstiacid//index.php/ekawan

Berdasarkan Pasal 18 ayat (3) UU PPh, maka Direktur Jenderal Pajak berwenang menentukan kembali besarnya penghasilan dan pengurang atas transaksi antara JAS dan Arjowiggins dalam menghitung penghasilan kena pajak JAS. Adapun metode yang digunakan untuk penghitungan ini bisa disesuaikan berdasarkan data dan informasi yang tersedia. Fakta pada kasus ini tidak ada mempermasalahkan adanya hubungan istimewa. Seharusnya Direktorat Jenderal Pajak mengungkapkan fakta ini terlebih dahulu untuk memastikan transaksi yang menjadi sengketa sesuai dengan peraturan perpajakan yaitu adanya hubungan istimewa.

\section{Bentuk Usaha Tetap (BUT)}

Pasal 2 ayat (5) UU PPh menjelaskan bahwa bentuk usaha tetap (BUT) adalah bentuk usaha yang dipergunakan oleh bukan Wajib Pajak dalam negeri, baik orang pribadi maupun badan, untuk menjalankan usaha atau melakukan kegiatan di Indonesia. Salah satu contoh BUT adalah pabrik. Penjelasan Pasal 2 ayat (5) UU PPh menerangkan bahwa dalam pengertian BUT mencakup:

1. adanya tempat usaha (place of business),

2. tempat usaha ini bersifat permanen,

3. tempat usaha digunakan untuk melakukan usaha atau kegiatan,

4. agen baik orang pribadi maupun badan yang kedudukannya tidak bebas dan bertindak untuk bukan Wajib Pajak dalam negeri, dan

5. agen asuransi dari perusahaan asuransi di luar negeri.

Article 5 mengenai permanent establishment (BUT) pada Perjanjian Penghindaran

Pajak Berganda (P3B) antara Indonesia dan Prancis (P. Indonesia \& Prancis, 1981)dijelaskan pada Tabel 2.

Tabel 2. Article 5 P3B Indonesia - Prancis

\begin{tabular}{|c|c|c|}
\hline Ayat & Bahasa Inggris & Bahasa Indonesia \\
\hline$(1)$ & $\begin{array}{l}\text { For the purposes of this Convention, } \\
\text { the term "permanent establishment" } \\
\text { means a fixed place of business in } \\
\text { which the business of the enterprise } \\
\text { is wholly or partly carried on. }\end{array}$ & $\begin{array}{l}\text { Untuk tujuan Persetujuan ini, istilah } \\
\text { "tempat usaha tetap" berarti suatu } \\
\text { tempat usaha tertentu di mana seluruh } \\
\text { atau sebagian usaha perusahaan } \\
\text { dijalankan. }\end{array}$ \\
\hline (2) huruf d & $\begin{array}{l}\text { The term permanent establishment } \\
\text { shall include especially ... (d) a } \\
\text { factory .... }\end{array}$ & $\begin{array}{l}\text { Istilah "tempat usaha tetap" terutama } \\
\text { meliputi ... (d) suatu pabrik .... }\end{array}$ \\
\hline (8) & $\begin{array}{l}\text { The fact that a company which is a } \\
\text { resident of a Contracting State } \\
\text { controls or is controlled by a } \\
\text { company which is a resident of the } \\
\text { other Contracting State, or which } \\
\text { carries business in that other State } \\
\text { (whether through a permanent } \\
\text { residence or otherwise), shall not of } \\
\text { itself constitute for either company } \\
\text { a permanent establishment of the } \\
\text { other. }\end{array}$ & $\begin{array}{l}\text { Jika suatu badan penduduk salah satu } \\
\text { Negara pihak pada Persetujuan } \\
\text { menguasai suatu badan atau dikuasai } \\
\text { oleh suatu badan penduduk Negara } \\
\text { lainnya pihak pada Persetujuan, atau } \\
\text { menjalankan usaha di Negara lainnya } \\
\text { itu (baik melalui suatu tempat usaha } \\
\text { tetap ataupun dengan suatu cara lain), } \\
\text { maka hal itu tidak dengan sendirinya } \\
\text { akan berakibat bahwa salah satu dari } \\
\text { perseroan itu merupakan suatu } \\
\text { tempat usaha tetap dari yang lainnya. }\end{array}$ \\
\hline
\end{tabular}

Sumber : Perjanjian Penghindaran Pajak Berganda Indonesia - Prancis. 


\section{EKONOMIKAWAN : Jurnal Ilmu Ekonomi dan Studi Pembangunan}

I55N : $1693-7600$ (Print), 155N : 2598-0157 (Online), hutp:/fumal.umstiac.id//ndex,php/ekawan

Terjemahan P3B dalam Bahasa Indonesia menggunakan istilah "tempat usaha tetap" sedangkan UU PPh mengunakan istilah "bentuk usaha tetap" untuk BUT. Adanya perbedaaan istilah ini tetap mempunyai makna yang sama tentang BUT.

Dalam menerjemahkan istilah "company", P3B ini juga menggunakan istilah yang berbeda yaitu badan dan perseroan. Dalam Artikel 3 ayat (1) huruf e pada P3B Indonesia Prancis ini, pengertian "company" adalah apapun jenis badan usaha yang dikenakan pajak penghasilan sebagai badan. Jadi berdasarkan UU PPh Indonesia, pengertian "company" ini adalah wajib pajak badan, yang bentuknya antara lain perseroan terbatas, firma, cv, yayasan, dan lainnya.

P3B Indonesia Prancis tidak menjelaskan apa yang dimaksud dengan isitlah "control" yang ada pada Article 5 ayat (8). Pengertian control menurut Merriam-Webster Dictionary adalah:

1. to exercise restraining or directing influence over (untuk menahan atau mengarahkan pengaruh).

2. to have power over (untuk memiliki kekuasaan atas).

Dengan melakukan sintesa antara pengertian control pada Merriam-Webster Dictionary dengan UU PPh, dapat disimpulkan bahwa adanya hubungan istimewa menurut UU PPh menjadikan adanya kontrol suatu Wajib Pajak terhadap Wajib Pajak lainnya. Adanya hubungan istimewa dapat mengakibatkan satu Wajib Pajak mengarahkan Wajib Pajak lainnya dalam melaksanakan usaha dan kegiatannya. Dengan demikian, maka pada Pasal 18 ayat (3) UU PPh mengapa dijelaskan DJP bisa menentukan kembali besarnya penghasilan kena pajak bagi Wajib Pajak yang mempunyai hubungan istimewa dengan wajib pajak lainnya.

Bila hanya melihat adanya hubungan istimewa antara JAS dan Arjowiggins dari sisi penggunaan teknologi, maka JAS bukan merupakan BUT dari Arjowiggins. Kesimpulan ini didukung oleh Artikel 5 ayat 8 dari P3B Indonesia Prancis. Namun demikian, bila di telaah lebih lanjut, diketahui bahwa:

1. JAS berupakan tempat usaha dan sifatnya permanen.

2. Tidak ada data bahwa Arjowiggins satu-satunya pelanggan JAS. Namun jika berdasarkan teknologi dan mesin yang digunakan JAS untuk menghasilkan produk, maka Arjowggins merupakan satu-satunya pelanggan JAS, karena:

a. produknya bersifat spesifik dan tidak bisa dijual ke sembarang pihak atau pihak lain,

b. teknologinya tergolong canggih dan tidak bisa ditiru, dan

c. ada kemungkinan monopoli pada hasil produk dan teknologi.

3. Jika dilihat dari dukungan Arjowiggins pada saat JAS mulai mendirikan pabrik dan proses awal produski, seolah-olah JAS merupakan pabrik milik Arjowiggins. Ini juga didukung dengan asumsi dari kenyataan bahwa Arjowiggins merupakan satu-satunya pelanggan JAS.

Dengan berdasarkan fakta, pembangunan pabrik JAS dibuat sesuai dengan keinginan Arjowiggins dan asumsi Arjowiggins satu-satunya pelanggan JAS, maka JAS secara substansi merupakan BUT dari Arjowiggins berupa tempat tetap berupa pabrik, walaupun secara legal formal dapat dibantah sebagai BUT.

\section{Tax Planning}

Secara substansi, JAS merupakan pabrik dari Arjowiggins untuk menghasilkan produknya dan dapat dikatakan bahwa JAS merupakan BUT dari Arjowiggins yang berada di Indonesia. Bila dilihat dari pengertian dari kata BUT, maka sebuah BUT seolah-olah 


\section{EKONOMIKAWAN : Jurnal Ilmu Ekonomi dan Studi Pembangunan}

I55N : $1693-7600$ (print), 155N : 2598-0157 (Online), hutp://fumal_umstiacid//index.php/ekawan

bukan badan usaha, namun suatu tempat atau aktifitas dalam melaksanakan kepentingan pihak lain. Dalam peraturan perpajakan di Indonesia, BUT lebih banyak di kenakan pajak dibandingkan dengan badan usaha yang merupakan subjek pajak dalam negari dan dengan subjek pajak luar negeri yang mendapatkan penghasilan dari Indonesia tanpa melalui BUT. Untuk mengurangi PPh di Indonesia, di duga Arjowiggins menjadikan JAS dalam bentuk badan usaha (Perseroan Terbatas) yang merupakan subjek pajak dalam negeri secara formalnya. Dalam melakukan proses bisnis, JAS bertindak sebagai BUT Arjowiggins di Indonesia.

Salah satu cara yang diduga digunakan Arjowiggins dalam menyamarkan BUT-nya di Indonesia adalah karena kurang lengkapnya pengertian control pada P3B. Dengan tidak ada penjelasan lebih lanjut dan lebih detil mengenai pengertian control pada P3B Indonesia Prancis, maka Wajib Pajak dari Prancis ini dapat menggunakan control pada penggunaan teknologi untuk melakukan pengurangan pajak di Indonesia. Wajib Pajak ini bisa menghindari adanya BUT dalam bentuk pabrik dengan cara mendirikan perusahaan yang tidak terindikasi adanya BUT sebagaimana diatur dalam Article 5 ayat (8) P3B Indonesia Prancis.

Apabila Arjowiggins menjadikan JAS sebagai BUT-nya di Indonesia sesuai dengan substansi transaksi yang ada, maka pajak yang harus dibayar Arjowiggins adalah:

1. PPh Badan sebesar $25 \%$

2. Branch profit tax pada BUT sebesar 10\% (diatur dalam P3B Indonesia Prancis). Branch profit tax adalah pajak yang dikenakan pada penghasilan setelah dikenakan tarif $\mathrm{PPh}$ (25\%) dengan kondisi laba dari BUT dibawa ke luar negeri.

Selain ada 2 jenis pajak yang dikenakan terhadap BUT, maka beban berupa quality control sesuai data pada putusan pengadilan ini tidak bisa dibeban oleh JAS karena pada prinsipnya antara JAS dan Arjowiggins adalah satu kesatuan entitas jika transaksi ini berupa BUT. Secara umum, pembayaran kepada kantor pusat oleh BUT yang tidak bisa menjadi biaya BUT adalah (Pasal 5 ayat (3) huruf b UU PPh):

1. Royalti atau imbalan lainnya sehubungan dengan penggunaan harta, paten, atau hak-hak lainnya;

2. Imbalan sehubungan dengan jasa manajemen dan jasa lainnya;

3. Bunga, kecuali bunga yang berkenaan dengan usaha perbankan.

Dengan strategi penghindaran bentuk BUT untuk pengurangan pajak, maka beban quality control yang dibayar JAS kepada Arjowiggins bisa menjadi beban JAS dan pembayaran beban ini merupakan cara untuk transfer penghasilan dari Indonesia ke Arjowiggins.

Strategi dengan menyamarkan BUT menjadi badan usaha di Indonesia lebih besar manfaatnya dibandingkan dengan strategi hubungan istimewa bagi Arjowiggins. Bila DJP mempersoalkan adanya hubungan istimewa karena penggunaan teknologi, dan asumsi terdapat data untuk menilai kembali nilai wajar transaksi antar pihak yang punya hubungan istimewa, dan DJP menang dalam sengketa ini, maka pajak yang dibayar JAS hanya bertambah sebesar $25 \%$ dari koreksi yang dilakukan DJP. Biaya quality control tetap bisa dibebankan oleh JAS walaupun ini merupakan transfer keuntungan ke Arjowiggins. Arjowiggins tetap terbebas dari branch profit tax. Strategi pengelakan pajak yang terbaik oleh Arjowiggins pada kasus ini adalah menyamarkan substansi BUT menjadi kerja sama antar pihak yang independen.

Strategi yang dilakukan Wajib Pajak ini dilakukan karena informasi yang dimiliki oleh Wajib Pajak lebih lengkap dibandingkan dengan yang dimiliki DJP dan ini sesuai dengan penjelasan Alm, Martinez-vazquez, \& Wallace (2009). Dengan mencermati strategi

Copyright@ 2020 , Ekonomikawan : Jurnal IImu ekonomi dan Studi Pembangunan. This is an open access article under the 


\section{EKONOMIKAWAN : Jurnal Ilmu Ekonomi dan Studi Pembangunan}

I55N : $1693-7600$ (print), 155N : 2598-0157 (Online), hutp://fumal_umstiacid//index.php/ekawan

ini, wajib pajak memindahkan profitnya ke negara domisili dan strategi ini sesuai dengan penjelasan Inger(2014), yaitu dengan menarik penghasilan dari luar negeri ke dalam negeri (dari Indonesia ke Prancis), maka akan mempengaruhi nilai perusahaan secara positif.

Melakukan strategi tax planning dengan cara mengubah bentuk usaha tetap di negara sumber penghasilan menjadi seolah-olah adanya bentuk kerjasama usaha dengan pihak yang independen, dapat mengurangi beban pajak perusahaan di negara sumber. Dengan informasi yang tidak dimiliki oleh otoritas pajak, maka strategi tax planning untuk pengurangan pajak akan berjalan dengan baik dan pemeriksaan oleh otoritas pajak tidak maksimal dalam pengurangan usaha wajib pajak untuk pengelakan pembayaran pajak.

Selain itu, adanya kekurangan dalam peraturan perpajakan bisa dimanfaatkan oleh wajib pajak untuk pengurangan pajak. Dalam kasus di Putusan Pengadilan Pajak ini, tidak ada peraturan yang menjelaskan bahwa:

1. BUT bisa saja dalam bentuk badan usaha yang legal, seperti perseroan terbatas,

2. pengertian BUT bisa dilihat dalam substansinya juga, bukan bentuk fisik saja,

3. istilah yang tidak dijelaskan pada P3B belum dijelaskan lebih lanjut pada peraturan lain, misalnya pengertian kata control,

4. penjelasan lebih detil mengenai hubungan istimewa karena penggunaan teknologi.

\section{SIMPULAN}

Pemerintah perlu dana untuk memenuhi barang dan jasa publik dan sebagian besar sumber dana ini diperoleh dari pajak yang dibayar wajib pajak. Di sisi lain, wajib pajak bertujuan menambah kesejahteraan dari usahanya sehingga berusaha untuk meminimalkan pajak yang harus dibayar. Terdapat dua pihak yang mempunyai tujuan saling bertentangan.

Negara melalui otoritas pajak melakukan pemeriksaan untuk memastikan pajak yang dibayar wajib pajak telah dibayar dengan benar sesuai peraturan. Wajib pajak akan menggunakan kelemahan peraturan pajak yang ada serta informasi yang dimilikinya untuk melakukan pengurangan pajak. Dengan kondisi ini, terlihat wajib pajak masih bisa melakukan tax planning untuk pengurangan pembayaran pajak ke negara.

Dengan menganalisis kasus pengadilan pajak yang dibahas ini, terlihat bahwa kelemahan peraturan dalam definisi bentuk usaha tetap (BUT) dan hubungan istimewa, maka wajib pajak bisa melakukan pengurangan pajak tanpa melanggar peraturan yang ada. Selain itu, tidak cukupnya informasi yang dimiliki otoritas pajak maka tindakan pengurangan pajak yang dilakkan oleh Wajib Pajak tidak terdeteksi dengan baik.

\section{DAFTAR PUSTAKA}

Allingham, M. G., \& Sandmo, A. (1972). Income Tax Evasion: A Theoretical Analysis. Journal of Public Economics, 1, 323-338. https://doi.org/10.1103/PhysRevE.71.062403

Alm, J., Martinez-vazquez, J., \& Wallace, S. (2009). Do Tax Amnesties Work? The Revenue Effects of Tax Amnesties During the Transition in the Russian Federation. Economic Analysis and Policy, 39(2), 235-253. https://doi.org/10.1016/S03135926(09)50019-7

Edaran, S. (1995). SE-18/PJ.53/1995. SE Direktorat Jenderal Pajak, Jakarta.

European Commission. (2006). Risk Management Guide For Tax Administrations (Vol. 1.02).

Hanlon, M., \& Heitzman, S. (2010). A review of tax research. Journal of Accounting and

Economics. https://doi.org/10.1016/j.jacceco.2010.09.002

Indonesia, K. K. R. (2015). Rencana Strategis Kementerian Keuangan 2015-2019. 


\section{EKONOMIKAWAN : Jurnal IImu Ekonomi dan Studi Pembangunan}

I55N : $1693-7600$ (print), 155N : 2598-0157 (Online), hutp://fumal_umstiacid//index.php/ekawan

Indonesia, P., \& Prancis, P. (1981). Perjanjian Penghindaran Pajak Berganda antara Pemerintah Indonesia dan Pemerintah Prancis. Pemerintah Republik Indonesia, (Jakarta).

Inger, K. K. (2014). Relative Valuation of Alternative Methods of Tax Avoidance. The Journal of the American Taxation Association, 36(1), 27-55. https://doi.org/10.2308/atax-50606

Lee, N., \& Swenson, C. (2008). World-Wide Corporate Tax Avoidance. University of Southern California, Los Angeles.

Lietz, G. (2013). Tax Avoidance vs . Tax Aggressiveness: A Unifying Conceptual Framework.

Lisowsky, P. (2010). Seeking Shelter: Empirically Modeling Tax Shelters Using Financial Statement Information. Accounting Review, 85(5), 1693-1720.

Ompusungu, A., \& Trisnawati, E. (2014). The tax audit, simplification of the tax return, perception of government spending and tax payer compliance. In SNA 17 Mataram, Lombok (pp. 1-18).

Pajak, P. (2018). PUT-115980.15/2014/PP/M.IIIA. Pengadilan Pajak.

Penata, I. R., \& Widyawati, D. (2018). Impact of a previous audit on tax aggressiveness of a firm taxpayer. Jurnal Dinamika Ekonomi Pembangunan, 1(3), 15-34.

Snow, A., \& Warren, R. S. (2007). Audit uncertainty, bayesian updating, and tax evasion. Public Finance Review, 35(5), 555-571. https://doi.org/10.1177/1091142107299609

Undang-undang Nomor 36 Tahun 2008. (2008). Pemerintah Republik Indonesia. Tentang Perubahan Keempat Atas Undang-Undang Nomor 7 Tahun 1983 Tentang Pajak Penghasilan, 23-09-2008, Lembaran Negara Republik Indonesia Nomor 4893, Jak.

Wang, X. (2010). Tax Avoidance, Corporate Transparency, and Firm Value. The University of Texas at Austin. 